\title{
Research on the Core Factors of Influencing College Students' Entrepreneurial Success Rate under the Perspectives of the Law and Team Management Perspectives
}

\author{
Yandong Zhang \\ Shandong Water Polytechnic,Rizhao,Shandong, 276826 China
}

\begin{abstract}
In this paper, we conduct research on primary core factors of influencing college students' entrepreneurial success rate under the perspectives of the law and team management perspectives. College students' entrepreneurship education is cultivating he students innovative spirit and creative ability as the basic value tendency, in order to cultivate creative talents as the main goal of education, it is an extension of the quality-oriented education, is the comprehensive development of students' qualities of wisdom education is the all-round development of students' personality education 'is pay more attention to the body of the human spirit, the humanist education. Carrying out entrepreneurship education, the reform and development of higher education to improve the quality of talent training levels promote national independent innovation and entrepreneurship has important significance. Our research proposes the novel perspective on the issues that is meaningful.
\end{abstract}

Keywords- Core Factors, Entrepreneurial Success, Law, Team Management, Perspective.

\section{Introduction}

At present, the college students' self-employment faces some of the difficulties which crack the development problem, encourage college student self-employment, university students' employment pressure for high quality business resources, to promote the transformation of industrial structure, that China's economic and social sustainable development has important strategic significance. Colleges and universities must carry out entrepreneurship education to the student, college students to realize the value preference of life is their own businesses, college students should take the initiative to adapt to complicated and changeable social environment, and actively respond to the challenges of future, further strengthen the cultivation of students' innovation spirit and practice ability is the contemporary social effective entrepreneurial education mode [1-3].

For the convenience of university students' employment, colleges and universities should be carried out among college students entrepreneurship education, guide students to view changes, are greatly, overcome the long-term planned economy formed employment dependent and change that to work in enterprises, government agencies to the idea of work, so that they become not only job seekers, and gradually become the pioneer of their own businesses and job creators which can create employment opportunities for oneself that also can create employment opportunities for more people. According to the literature review, the functionality of the entrepreneurial activities could be summarized as follow. (1) College students' self-employment is an important approach to promote the transformation of the industrial structure. Master the cutting-edge knowledge, rich imagination and general creativity of the entrepreneurial university graduates, whether in the factors of production, and production efficiency, with the traditional business has essential difference. Look from the use of factors of production, the traditional business relies mainly on the non-renewable resources and energy with college graduates entrepreneurship relies mainly on the renewable ideas. (2) The college students' self-employment 
is to realize agglomeration of fast high-quality labor force in our country. Central and local governments at various levels shall be issued a series of measures, venture funding for modern university graduates, entrepreneurship training, entrepreneurship and innovation service platform, actively guide college students to shift their concept of employment promoting entrepreneurship to create more employment opportunities, trying to change the heavy employment pressure for high quality business workforce.

Entrepreneurial process is a phased, at different stage of youth entrepreneurship team psychological compatibility levels, as well as the psychological compatibility fairness perceptions by team and team cohesion performance impact strength may present a certain differences. Some youth entrepreneurial teams because of the lack of the mature internal management system, make them in the case of low psychological compatibility conflict lacks reasonable, standard solution mechanism, are more likely to have a negative impact on performance. How to deal with these issues will be important.

\begin{tabular}{|c|c|}
\hline $\begin{array}{c}\text { Management } \\
\text { (structure) }\end{array}$ & $\begin{array}{c}\text { Leadership } \\
\text { (ffexibility) }\end{array}$ \\
\hline A function & A relationship \\
\hline Planning & Selecting talent \\
\hline Budgeting & Motivating \\
\hline Evaluating & Coaching \\
\hline Facilitating & Building trust \\
\hline
\end{tabular}

Figure 1. The General Principles of the Team Management

In this paper, we conduct research on core factors of influencing college students' entrepreneurial success rate under the perspectives of the law and team management perspectives. In the following parts, we will propose and analyze our perspectives in detail.

\section{The Proposed Methodology}

The College Students' Entrepreneurship. College students' entrepreneurial activities began in the 1980 s. In 1983, the United States, the university of Texas at Austin, two MBA students held the first business plan competition, soon after, such as MIT, Stanford university world first-class universities' more than 10 universities such contests every year, after is popular all over the world.

Entrepreneurship education is to cultivate students' creative personality while inspires the students innovation consciousness that causes the student to master the business knowledge at the same time, the creative desire and impulse. First, strengthen the education of national spirit, causes the student to national development and revitalization of the combined with their own responsibility and mission, this is the power of entrepreneurship education, combined with a variety of forms to the national spirit education for students in innovative entrepreneurial spirit to help students set up the spirit and ideal.

Entrepreneurship, just as its name implies is founded. In a narrow sense refers to people with the ability to create new career, start new businesses. Meaning in the broadest sense of the very broad: and some entrepreneur is the owner himself, also is to be my own boss, made his own business that is a business that some belong to the managers, but on the post diligent, conscientious which has made achievements, recognized by society and find his own position, and entrepreneurship. As for modern college student, they are facing with the listed challenges [4-5].

- Innovation. Entrepreneurship as far as possible based on the independent intellectual property rights, China's international commitments for the protection of intellectual property rights organization mainly through to protection of intellectual property rights and the international conventions, or bilateral agreement in the form of agreement, lack of protection. 
- Knowledge. In numerous entrepreneurship competition plans, we found that many of the entrepreneurs cannot express the primary ideas accurately and clearly, the lack of personalized information, some plan or even.

- State of mind. Entrepreneurs need rational but not impulsive, the entrepreneurs need to calm rather than enthusiasm, college students for the entrepreneurship in reality as the "great leap forward", seems to open a company will happen overnight, will bonanza.

- Experience. Opine, encouraging words, college students' ideals and aspirations is some, but "expectations", besides can "theory" in the entrepreneurial process, as lack of specific market development experience and relevant knowledge. Inexperience, the lack of integration of the resources, from the angle of professional management ability is one of the important reasons for the college students' entrepreneurial failure.

The Entrepreneurial Team Management Principles. Heterogeneity of top management team with both companies copes with the external the dynamic and complicated environment and related to enterprise need to improve the quality of decisions. But, about the relationship between the degree of heterogeneity and decision quality, and match the response to the external environment such as level of heterogeneity relationship has not unified research conclusion.

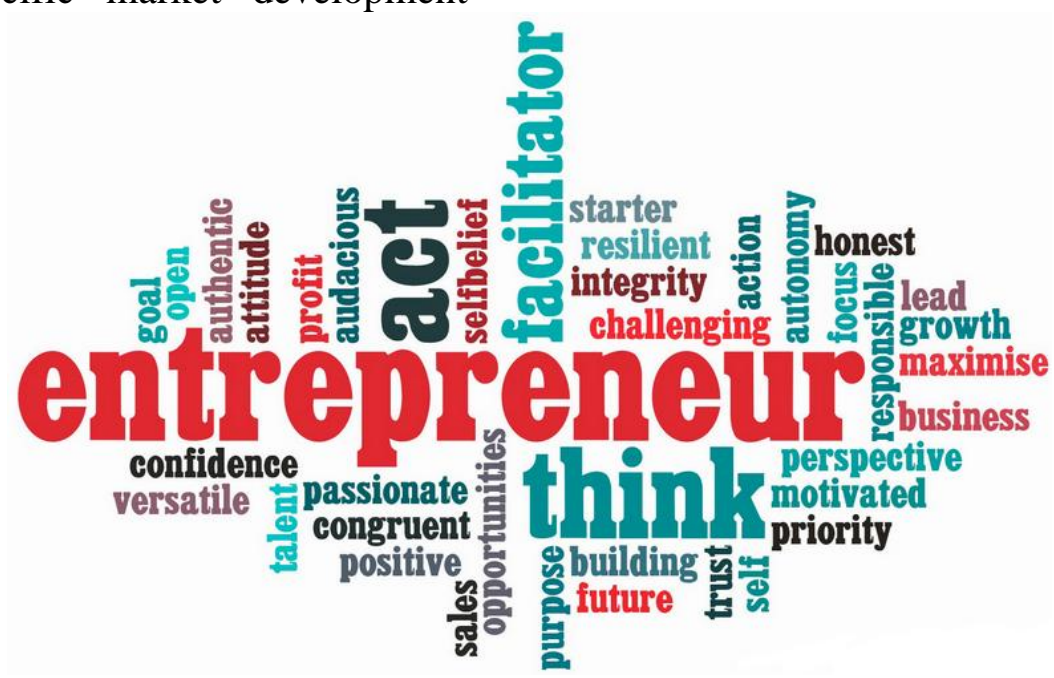

Figure 2. The Keywords of the Contemporary Entrepreneurship

High-tech venture enterprise core value driving factor is the human capital, especially the technical team before the human capital in the transformation of the enterprise organization capital and human capital owner is inseparable while the enterprise legal owners only through appropriate institutional arrangements to motivate and control. The basic principles of general entrepreneurial team could be summarized as the follows. (1) Honesty and integrity. It is beneficial to customers, the company code of conduct and value creation. It repels pure pragmatism or self-interest that refused to the narrow interests of the individual and departmental interests. (2) Cohesion. The concept of having the right team members believes them in the midst of a community of destiny, Shared benefits, and risks. Team work, that is, as a team rather than individual work "hero", each person's work depend on each other and support, rely on your success to inspire everyone. (3) Committed to value creation. The 
other who have the right team commitment to everyone and make the "cake" bigger, including increased value for customers, make the suppliers as the team success and benefit, for the team all the supporters and the various stakeholders benefit and gain [6].

In the condition of complete information, the game to get to know each other, if the game has a very good cooperation history and the trust each other, they are more likely to choose cooperation to maximize the interests of both sides. Dynamic model, illustrates the repeated game, the game process between existing can help players get to know each other, and as a decision-making basis for the next game. Relative to the imperfect information condition of static model, and dynamic model and state model with complete information more widely exist in real life. Helps group members psychological compatibility between mutual respect, trust, and emphasizes the fairness and the justice of Chinese traditional culture and group thinking, the mutual respect and trust within the group members must perceive higher fairness, stronger team members' cooperation and cohesion will therefore ascension.

The Business Law. College students is a special social group, the advantage of its business mainly include: young has the vigor, the courage to fight as professional quality is higher as strong learning ability and have entrepreneurial spirit with the use of network capability is strong. This makes college students a unique advantage of business people, become a potential business to nurture and support. College students' entrepreneurship will also become a social trend, more and more people will choose their own businesses, for this trend, we need government support and promote.

Student entrepreneurship policy has risen to the necessity of the legal system should be analyzed from the listed aspects. (1) The legal system. Legal system refers to the use of legal norms to adjust the various social relations formed by various systems as the legal system has the relative boast skillful, stability. At present, our country there is no legislation concerning college students' entrepreneurship. (2) Legal system is in the policy, there are the advantages of current promoting college students' entrepreneurship, the construction of the legal system is the inherent demand for the college students' entrepreneurship, is also the inevitable need of college students entrepreneurship policy. So, it is necessary to put the college student entrepreneurship policy to rise to the level of legal system. (3) Policy refers to the standardization of organs of state power in the form of authority to rule on the provisions of the certain historical period. Policy is temporary, variability and at present, the college student entrepreneurship policy more. Based on legal aid of expanding the range of the application, entrepreneurship the object of the legal aid application for college students only as the college student group should be able to do and other preferential policies to enjoy group is consistent, namely fresh graduates or within two years after graduation to engage in entrepreneurial activities of students.

The Entrepreneurial Success Rate. Entrepreneurship education practice is necessary condition of successful entrepreneurship education while the entrepreneurship education is closely related to the entrepreneurial practice, attaching importance to and the entrepreneurship practice activities improve their entrepreneurial skills, let students know themselves in the entrepreneurial practice to improve myself, looking for accurate positioning, to entrepreneurial groundwork for the future [7].

Entrepreneurship practice is concrete application of entrepreneurship theory and entrepreneurship practice, designed to let students experience the entrepreneurial process, be familiar with business elements, prepared to entrepreneurship, contribute to general business success. The basic purpose of entrepreneurship education is to promote entrepreneurship practice, promote the transformation of science and 
technology and entrepreneurial education achievements, successful business practice and verify the results of entrepreneurship education that effectively promote entrepreneurship education better which should pay attention to the listed suggestions.

- To further improve the macro environment of the entrepreneurship. In implementation, on the basis of current college student entrepreneurship support policy, can according to the college students' entrepreneurship practice that conforms to the local college student entrepreneurship policy, improve the college students' venture legal environment.

- Improve the college students' venture capital safeguards. Countries can set up the college students' venture fund, local governments, colleges and universities to match, from starting a startup hub, policy field, financial support and so on to provide favorable conditions and to ensure implementation.

- In practice base construction and the propaganda on the business results. State and the local governments can work together for a group of college student entrepreneurship training and practice base, the demonstration base of entrepreneurship [8].

- Strengthen entrepreneurship education school, is to optimize the entrepreneurial education mode, cultivate and form a good entrepreneurship education teachers, not only to provide the theory support for students of entrepreneurship, but also try to establish students pioneer park, let the student to practice, experience the hardships and happiness in the basic process of the entrepreneurship. So as to stimulate the students' entrepreneurial zeal unceasingly, make more students to try to entrepreneurship, through this a series of process of experience, there will be more and more people of entrepreneurial success.

\section{Conclusion}

In this paper, we conduct research on core factors of the influencing college students' entrepreneurial success rate under the perspectives of the law and team management perspectives. College student entrepreneurial model refers to the college students in a specific area formed in the modern specific environment, in the way of entrepreneurial motivation, entrepreneurial organization form, industry to enter, fund-raising which has similar figures and typicality of entrepreneurial behavior as is all sorts of entrepreneurial factors configuration mode. In addition, for business plan design and the choice of innovation model correlation, as well as the business plan of the organization plan and entrepreneurial team combination of empirical research, relatively lack. Under this background, we propose the novel perspectives on the college students' entrepreneurial success rate that is innovative.

\section{References}

[1] Falck, Oliver, and Ludger Woessmann. "School competition and students' entrepreneurial intentions: International evidence using historical Catholic roots of private schooling." Small Business Economics 40.2 (2013): 459-478.

[2] Falck, Oliver, Robert Gold, and Stephan Heblich. "Lifting the Iron Curtain: Schooling and Entrepreneurial Intentions of Students." (2014).

[3] Lin, B. A. I., and Y. A. N. G. Xia. "Entrepreneurial Ability Training of the Economics Management Students Under the Condition of Virtual Simulation." (2015).

[4] Israel, Katura James, and Dakung Reuel Johnmark. "Entrepreneurial Mind-Set 
Among Female University Students: A Study of University of Jos Students, Nigeria." Chinese Business Review 13.5 (2014).

[5] Otuya, Robert, et al. "Entrepreneurship education: Influencing students' entrepreneurial intentions." International Journal of Innovative Research \& Studies 2.4 (2013): 132-148.

[6] Hallam, Cory, Anita Leffel, and Raúl Calvoz. "Identification of Temporal Construal Effects on Entrepreneurial Employment Desirability in STEM Students." Journal of Entrepreneurship 24.2 (2015): 204-222.
[7] Laguador, Jake M. "A correlation study of personal entrepreneurial competency and the academic performance in operations management of business administration students." International Journal of Academic Research in Business and Social Sciences 3.5 (2013): 61.

[8] Marchese, Maurizio, et al. "The EIT Digital Master School: A Program to Foster the Education of Entrepreneurial, Innovative and Creative Students." Creating Innovation Leaders. Springer International Publishing, 2016. 255-266. 